\title{
Innovative Course Delivery using Analyze - Group - Design - Optimize (AGDO) Methodology: Case Study of Entity-Relationship Model
}

\author{
Aparna Sharma*, Rishabh Singh, Prathamesh Churi, Mahesh Mali \\ School of Technology Management and Engineering, NMIMS University, Mumbai, 400056, India
}

\begin{tabular}{l} 
A R T I C L E I N F O \\
\hline Article history: \\
Received: 12 August, 2020 \\
Accepted: 25 September, 2020 \\
Online: 12 October, 2020 \\
\hline Keywords: \\
AGDO \\
Design \\
Group \\
Analyze \\
ER Diagram
\end{tabular}

A B S T R A C T
Visualization plays an important role in teaching and learning. The ability of the learner to
grasp the visual contents are better than that of textual contents. Traditional teaching
methods often revolved around instructions and recitation techniques. However, most of
these approaches were dormant and did not call for active learning. The proposed AGDO-
Analyze, Group, Design \& Optimize methodology was inspired by these obstacles and
creates an engaging and wholesome experience for the students. A sample of 47
undergraduate students was used to analyses the feasibility and effectiveness of this
teaching mechanism. Students first tackled and analyzed the problem statement with their
preconceived knowledge. They were then segregated into groups wherein they designed
solutions collectively. Finally, they tried to find an optimized solution considering all the
suggested designs. Observations were validated based on feedback and how well the
students were able to perform. The results revealed that approaches such as AGDO
facilitate an immersive learning environment and ensure the quality of teaching. The
implications and methodology were further discussed.

\section{Introduction}

The current education system in our country has been blamed for all sorts of evil for hundreds of years. Rote learning is still a trouble for our education system, students mug up concepts/theory/methodologies to score marks. The main problem associated with the system is the lack of effective learning pedagogies [1], [2], knowledgeable instructors, and trusted online content. The current assessment process comprises testing the crammed information presented on paper, in such cases the knowledge and skill are given less importance. Teaching pedagogy must emphasize skill-based development which will help students in their professional life [3], [4]

The research work done in [5] reveals the fact that the use of digital video in the classroom increases student engagement. According to the case study in [5]

- It helps to increase the student's motivation to study.

- The learning experience is enhanced.

- Students may get good marks if they are made interested to learn the topic.

\footnotetext{
${ }^{*}$ Corresponding Author: Aparna Sharma, NMIMS University,
}

sharmaaparnasunil@gmail.com
- It also increases the team building and communication skills.

Many researchers have observed, learners can gain positive indicators when they watch authentic and real-life clips [6] Information and communications technology is influencing the delivery of education in tertiary institutions. Researchers studied video usage and student beliefs about video instructions for 'beyond classroom' learning and concluded that videos are preferred by students as learning tools compared to other online learning media [7]. In a study conducted, one of the five reasons cited for effective teaching was easy to access to taped teaching sessions, hence rendering the use of video technology in the teaching-learning process as critical [8]. The implementation of this process is not without difficulties. Finding relevant and objective videos that are of optimal length is a challenging and time-consuming task [9]. The proposed AGDO methodology focuses on skill-based learning and makes use of video and audio tools to solve a case study. We agree that it does not apply to all the complex engineering problems.

We conducted a case study on 47 students, in which they had to follow the process of the proposed model. The students were given a problem statement that demanded the development of an entity-relationship model by them. In the initial stage, all students individually analyzed the given problem statement using some 
media as a resource for the same. This media including text, images, and videos. After the analysis, the students were grouped and they had discussions about the problem statement and their respective analysis. By listening and understanding the analysis done by every student in the group they moved towards designing the model. The students adapted and improvised on the group's model based on their discussion, the key towards the development of an ideal model lied in the decision making and choices of the groups. After receiving the models from all the groups, their strengths and weaknesses are discussed. The models need to be compared and evaluated to obtain the most suitable model applying to the problem statement through optimization.

Through this research, we are proposing a model that helps the students and teachers to obtain better results by following four basic procedures of A-G-D-O that are- analyze, group, design, and optimize. Apart from the proposed model our results also showed an enhanced understanding level of concepts by the students while using visual data like images and videos rather than the traditional textual way. The study showed a gradual increase in effectiveness with the increase in visuals and animations i.e. from text to images and videos.

\section{Motivation}

\subsection{Skill-based learning}

Skill Based Learning (SBL) [10]-[12] is an adaptive method that provides students with external knowledge that is suitable for a particular skill. Psychological research says that by having students learn through the experience of solving problems in place of rote learning, they can learn both contents of study and analyzing strategies [13], [14]

In SBL, student learning focuses on a complex and innovative problem rather than a simple and traditional problem that does not have a single correct answer. Identifying appropriate complex and innovative tasks is the role of an instructor. A complex problem is a problem in which there are multiple ways to solve the problem OR may have to use multiple strategies or algorithms to solve a problem. A complex problem doesn't have a normal and direct answer, it requires thinking and analytical skills which always comes through experience.

According to recent research, Skill Based Learning helps in the following way:

- Motivating creative skills - SBL helps to think out of the box and motivates creative skills to solve a particular problem.

- Develops critical thinking [15]- SBL helps students to hone analytical and critical thinking skills in all the topics. In this way, rote learning can be avoided, and self-learning can be motivated.

- Enhances collaborative problem solving [16] - Constructive criticism is always necessary to solve a problem in the real world. This is only possible if students learn how to work collaboratively in a group in a selfless way. Skill-based learning helps in drawing enhancing strengths and important skills to achieve their goals. While organizing an event or a field-based activity, students work as a team to deliver the desired results.
- Builds effective written and oral communication [17] SBL helps to improvise written and oral communication through reports, presentations, seminars, etc.

- Hones leadership - SBL in classrooms also helps to develop leadership skills in students and help them see beyond their self-interests.

However, it is difficult to indulge in the culture of analyzing the things in students by the teacher. A graphical representation/ pictorial view/video can be used to analyze the concepts better [18]. The advantages of Video and Graphics/Image are tabulated in Table 1.

Table 1: Advantages of the use of Text, Images, and Videos in SBL

\begin{tabular}{|l|c|c|c|}
\hline \multicolumn{1}{|c|}{ Parameter } & Text & $\begin{array}{c}\text { Images } \\
\text { /Graphics }\end{array}$ & Video \\
\hline $\begin{array}{l}\text { Facilitating } \\
\text { thinking and } \\
\text { problem solving }\end{array}$ & $\mathrm{X}$ & $\checkmark$ & $\checkmark$ \\
\hline $\begin{array}{l}\text { Inspiring and } \\
\text { engaging students }\end{array}$ & $\mathrm{X}$ & $\checkmark$ & $\checkmark$ \\
\hline $\begin{array}{l}\text { Easier to be } \\
\text { accepted by } \\
\text { students }\end{array}$ & $\checkmark$ & $\checkmark$ & $\mathrm{X}$ \\
\hline $\begin{array}{l}\text { More than words } \\
\text { can tell }\end{array}$ & $\mathrm{X}$ & $\checkmark$ & $\checkmark$ \\
\hline Inspired Thinking & $\mathrm{X}$ & $\checkmark$ & $\checkmark$ \\
\hline
\end{tabular}

\subsection{Effect of Textual Data, Images, and Videos on Human Brain}

Humans are social creatures. They have metamorphosed to communicate in forms of stories, ideas, and visions. Digital storytelling endeavors to stimulate real-life ways of understanding and communication. This allows humans to acknowledge and conceptualize the idea, which is a stark contrast to the notion of the traditional methodology of imparting knowledge through textual scripts [19]. Similarly, a study conducted by Teleiquile also pointed to the fact that people acquire $83 \%$ knowledge from vision, $11 \%$ from hearing, and 5\% from other sources [20]

With the digital boom all over the world, digital technology has become a part and parcel of one's life. These digital reformations have impacted the entire world dynamics, including the field of education [21]. Multimedia such as engaging images and videos arouses interest and enthusiasm. Images and videos accede students in going beyond the four walls of a classroom [22].

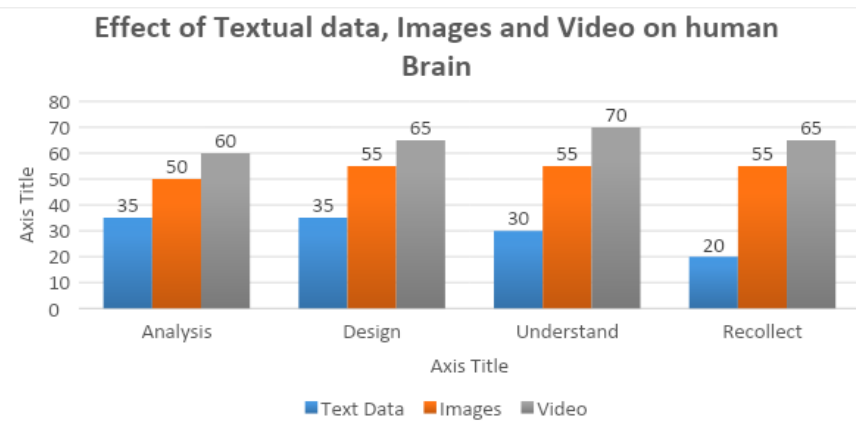

Figure1: Effect of Textual Data, Images, and Video on Human Brain

The problem statement was exercised with a group of 47 students. It was performed and segregated into three levels. 
Students were entrusted with a problem definition in different forms and a survey was conducted thereafter, to analyze their understanding for the same. Level One consisted of the problem statement as a two-page textual script. In Level Two, the problem statement was depicted in the forms of images, similar to comics. In Level Three, a five-minute video was outlined in front of the students. All the three stages were recorded and the survey divulged the following results(See figure 1):

\section{AGDO Methodology}

In the proposed Analyze-Group-Design-Optimize (AGDO) method students work individually as well as in groups to identify basic requirements to solve a real-time complex problem. The AGDO methodology makes use of Graphical con-tents and SkillBased Learning as described in previous sections. Students get engaged in self-learning and then apply their knowledge to the problem and reflect on what they learned. The instructor acts as a mentor who is passively involved in the learning process rather than actively providing knowledge.

The block diagram of AGDO methodology is drawn in figure 2 below. The diagram depicts the outcomes and strategies of each keyword with the description.

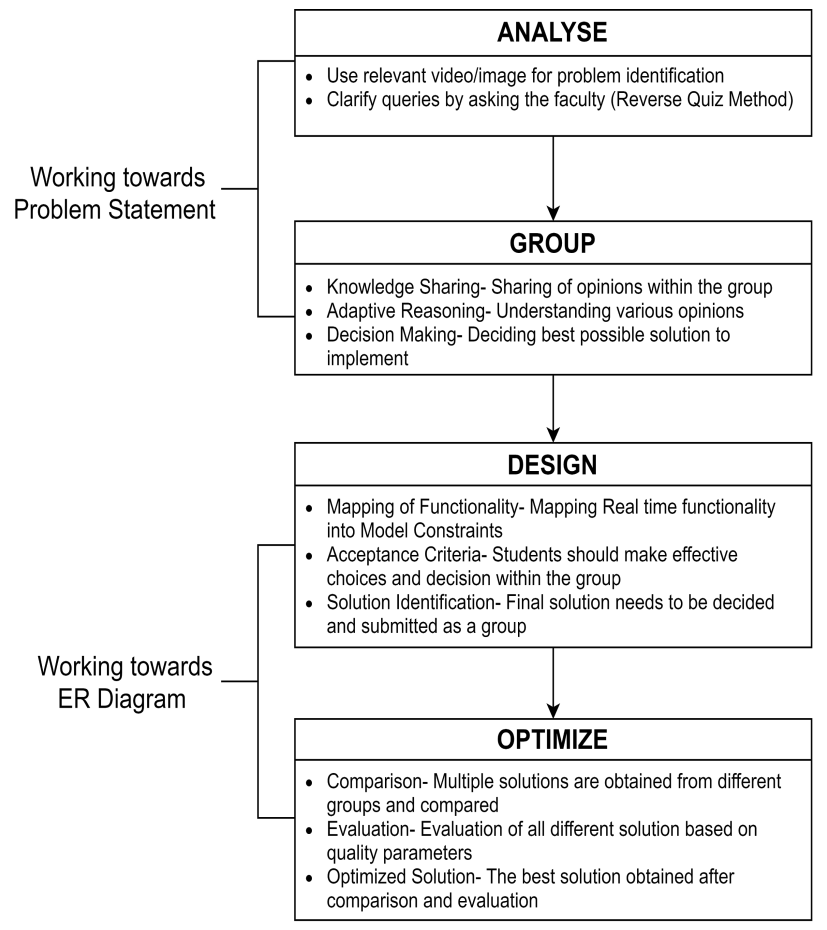

Figure 2: AGDO Methodology Block Diagram

We have experimented with our proposed AGDO methodology for conducting database management lectures to teach data modeling (Entity-Relationship Model). In the proposed AGDO methodology, students will be provided with visual artifacts to analyze the real-time problem and model an EntityRelationship Model. By forming groups students will get an opportunity to collaborate and come up with different ideas. By using Adaptive reasoning and Decision-making ability of each group to map functionalities of the system in the designed ER diagram. Each group would present their proposed solution, these individual solutions would be evaluated and updated to arrive at an optimized solution.

\section{- Analyze}

Individual students will analyze the real-time problem using relevant videos/images to felicitate thinking and problem defining abilities. Instructors will continuously monitor progress using the reverse quiz [23] method. The conceptual understanding and progress of the students are confirmed by asking them questions about the same in the reverse quiz method. With a proper understanding of the problems by the students and assurance of the same by the instructors, we move on to the next phase of our model.

\section{- Group}

The students are then grouped and asked to have discussions about their analysis by the instructors. Group discussion will ensure active participation and the process of learning by listening to others. Adaptive learning will promote selfdetermination [24]-[27] among students to provide and accept design decisions proposed by peers. The formation of groups provides several different ideas as well as induction of innovation among peers. Listening skills are a key to this process, better understanding within the group results in better model development. After acceptance of the solution proposed by the peers, groups start with the designing phase of the model.

\section{- Design}

After the discussion, adaptation, and improvisation of their respective analysis. Students will come up with mapping realtime functionality into model constraints. Groups will decide the acceptance criteria to make effective choices and decisions within the group. The final solution will be proposed by the project team [23].

\section{- Optimize}

All the models developed by every group are collected, discussing the positives and negatives of each. Selecting one model for any problem statement in most cases would not result in the ideal solution. Hence, all proposed solutions are compared and evaluated to obtain the best possible solution using presentation by the groups.

\section{Case Study using the AGDO Methodology - Entity- Relationship Model}

A case study approach [28] allows us to explore real-life scenarios in a given sample size and identify solutions. Hence, this case study was established to give ideas for designing data models for students. It was effectively conducted with students of Semester III, Computer Engineering who had merely basic knowledge of design process and methodologies. The main objective of this case study was to make students aware of innovative and practical strategies to conceptualize problem statements and eventually, draw ER diagrams for the same. The course name was Relational Database Management System. The total time required for this case study was four hours.

The case study involved following the AGDO methodology and hence conducted in four buckets- Analyze, Group, Design \& Optimize. See Figure 3 for the given problem statement. 


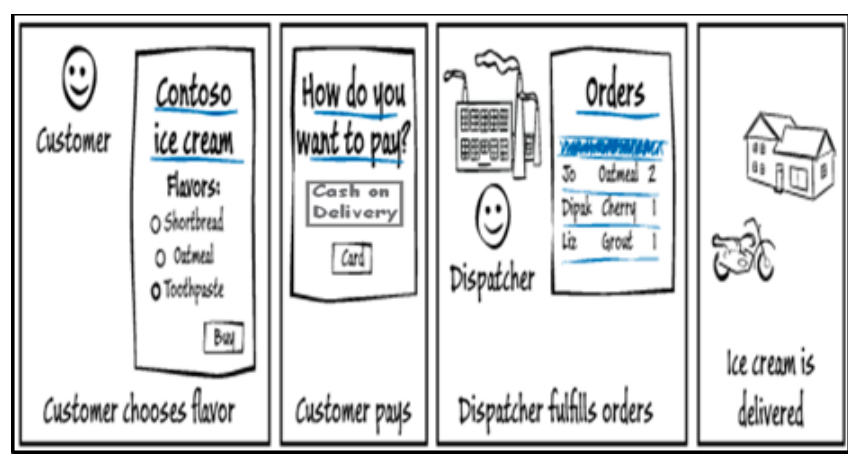

Figure 3: Problem statement

- Analyze: A group of 47 students was presented with the above picture. The problem statement involved forming a Relationship Entity Model based on the given picture. The students were expected to analyze the given problem statement, connect it with pre-existing knowledge, and form initial grounds of approaching this problem statement. The system environment consisted of a typical ECommerce, involving customers (consumers), shopkeepers (vendor), and dispatchers (distributor).

The problem definition of Figure 3 is as follows:

The CoolPoint Ice Cream Delivery System has many flavors of ice cream. The system will allow customers can choose flavors of ice cream from the list, Customer places the order and pays the bill through card or chooses to pay on delivery, Staff gives the order dispatching list to the dispatcher and the dispatcher delivers the ice-cream orders to the respective customers. The system environment is for Customer, Shopkeeper, and Dispatcher.

- Group: After analyzing, the students were now grouped into clusters, containing 4 to 5 students. The team goal is to help one another understand the problem statement successfully and to identify the purpose. Each member of the group was accountable individually and collectively. Every member of the group had to work towards a common goal and perform his/her tasks that contribute towards it. In smaller groups, students could now freely discuss and debate their ideas. They also learn by effectively listening [29] to other peers to express their ideas. Grouping calls for an engaging and more confined platform which lets students feel much more confident and accepted within the smaller constraints of a group.

A sample outcome of this step (Referring figure 3) is given below:

\section{Identify Entities and attributes for each entity.}

- To identify entities from the scenario we can use the 'Noun-phases' approach.

- This approach considers all nouns and phases in the problem as entities.

- Then we will take some steps to remove all vague or unnecessary Entities

- If an entity is depending on other entities or entities not having independent existence in the system such entities are enlisted as Weak entities.
Some problem attributes are given in the problem statement itself. Sometimes attributes are not specified in the problem.

\section{Example Above:}

IceCream (Flavor, pricePerScoop)

Customer (Customer_Name, Customer_Mobile, Cust_Address)

Shopkeeper (Customer_Name, Customer_Mobile, Cust_Address)

Dispatcher (Order_Id, Shipping_Address, Ship_Status)

- Design: The third step involved them working collaboratively to build on the designing of the ER model. Completion of the ER diagram required each student's work to be combined with that of other students to produce a team effort. They started designing the model by forming and recognizing primitive stages of relations such as (see Figure 4 and 5):

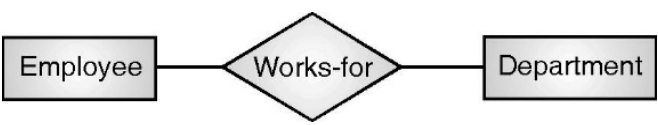

Figure 4: Formation of relationships within entities

\section{Approaches to Identify Relationships}

- We can use conjunction used in problem for naming relationship.

- Example, Employee works for a department

- We can also use the name of two entities connected with an underscore as a conjunction for the naming relationship.

- Example, Employee works for a department

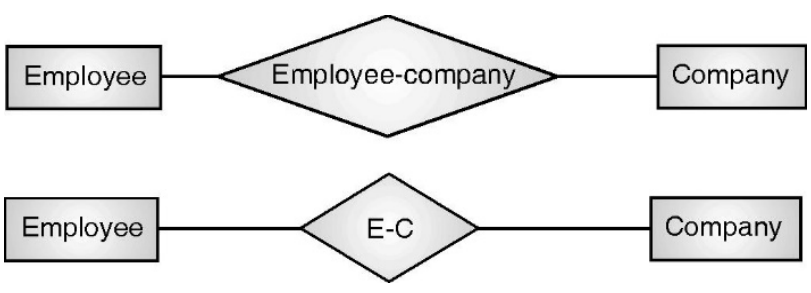

Figure 5: Formation of relationships within entities

- Optimize: This problem statement which closely tried to mimic real-world problems, had a wide range of parameters and constraints. The smaller clustered groups presented their contrived designs in front of the entire class. They gave and received feedback on their presented solution. The class then tried to find the optimum solution by comparing all the suggested diagrams by the various groups. The optimized solution was an amalgamation from diagrams received by various groups.

\section{Results and Analysis}

The usage of AGDO methodology accorded students the skills required to understand real-world problems using visual artifacts such as videos and images. The analyzing stage empowers them to use preconceived knowledge and relate it with the given problem statement. Reverse questioning can lead to a better conceptual 
understanding [30] while ensuring continuous assessment by the teacher. Hence, making sure that the results of the analysis obtained are relevant to the topic. The grouping stage allows students to work together and share experiences which leads them to a better understanding of the problem at hand and integrates different perspectives. The designing data model in the group will improve the acceptability of solutions from other peers. Students experience active learning through problem-solving, brainstorming sessions, and group assignments for designing the solutions.

This case study was conducted with the help of student teams in a session regarding RDBMS during a class. After following the proposed AGDO methodology, the student teams came up with multiple solutions, and the one shown in figure 5 was found out to be the optimal one.

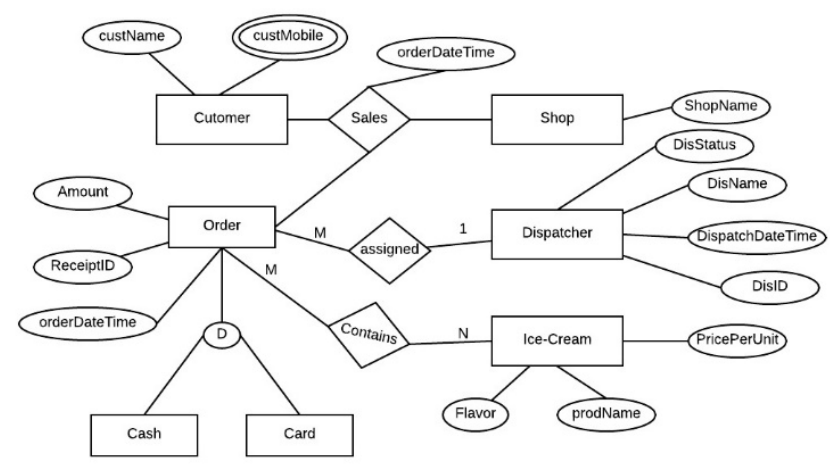

Figure 5: Optimized Solution

This led to the introduction of various metrics such as Problem Statement, Questions, Solutions, and Learning Outcomes that help affluently evaluate the proposed approach. Students were graded according to their performance on these parameters.

The following results can be drawn out of the assessment of the case study post implementing the AGDO methodology: Greater than half the strength of the course, $55.5 \%$ (26) of students scored over $90 \%$ in successfully understanding and conceptualizing the problem statement. This led us to the direction that students were able to harness the given visual artifacts into meaningful and coherent comprehension. In the category labeled 'Questions', it was observed that $44 \%$ of the class could surpass the $80 \%$ threshold. This paves the way for the reverse questioning method and group discussions which stimulate and encourage students to probe and ask questions, thereby fueling their curiosity. Similarly, $40.4 \%$ (19) scored more than $80 \%$ for the solutions that they provided for the given problem statement. $72.3 \%$ (34) of students secured over $80 \%$ when evaluating the learning outcomes. This, in turn, gave better insights into potential subject outcomes, thus accelerating learning and growth.

In totality, $42.3 \%$ (16) of the total students attained above $90 \%$ of the maximum marks allocated, while a staggering $93.6 \%$ (44) were able to achieve over $80 \%$ of the maximum marks. These numbers substantiate the proposed AGDO methodology.

The students gave feedback about the usage of this case study regarding their learning of viewing real-world scenarios for designing IT solutions. Students got the experience of active learning through problem-solving, brainstorming sessions, and group assignments for designing Real-World Systems. Feedbacks provide better insight and help verify the feasibility and efficacy of the proposed method.

Feedback was provided by the 47 participating students on various parameters. They were asked to give the rating on a scale of 0 to 5 , zero being the least effective to 5 being most effective. For the first two parameters which were based on the relevancy and ease of understanding of the course, it was observed that images were the most effective medium. While the latter two which were based out of helpfulness and the overall impact indicated the video was the most preferred option. In all four parameters, the textual transmission was rated relatively poorly proving that it was not favored amongst the students. This table reaffirms the advantages of visual artifacts such as videos and images over textual data.

\section{Limitations of the AGDO Methodology}

AGDO methods motivate skill-based learning and encourage the group working culture among engineers. In industry. Working together in a group is the most important aspect. Engineering leadership is another emerging area of research [31]. The courses like software engineering, Technical Project, Mobile Application Development, Prototype Development, etc. wherein the problem definition and problem formulation is involved, the AGDO methodology is best suited. The theoretical subjects and other selfstudy-based subjects, the AGDO courses are not appliable.

Another limitation of this paper is the sample size, which is very small for any kind of analysis. Since AGDO methodology was new, we have tested its applicability on a smaller population. In near future, we would like to extend our work to a larger population and we would like to conduct the statistical measures to prove how AGDO methodology helped to build a perfect ER model.

\section{Conclusion}

There is evidence that suggests that the traditional education reforms, once considered significant, are now struggling to keep up with modernization. Historically, students often resort to ineffective methods such as rote learning or often feel disengaged from the learning process. In the AGDO modus operandi, it tries to eliminate the above by students working collaboratively in groups towards a common goal.

As a denouement of the case study, students were able to discover and learn the subject of the course on their own by questioning, interrogation, and logical ability. Grouping allowed them to weigh, judge, and preview others' ideas with their own. This sanctioned them to construct and assemble ideas which were also accepted by their peers. By using their primary knowledge and associating it with daily life, they were able to optimize the best possible outcome and come up with scalable and practical solutions. AGDO strives to foster an easy understanding of concepts and bring joy to learning. To conclude, this study showed that AGDO is an effective teaching method.

While applying this methodology, it was also observed that in most cases students using visual forms of data like images and videos had better efficiency than that of the students using traditional textual methods. This was a result of the increasing 
proficiency of students in technology and a better understanding of concepts through visualization rather than textual descriptions.

\section{References}

[1] G. Domik, Fostering collaboration and self-motivated learning: Best practices in a one-semester visualization course, IEEE Computer Graphics and Applications, 2012.

[2] H. J. Holz, A. Applin, D. Joyce, H. Purchase, C. Reed, B. Haberman, Research Methods in Computing: What are they, and how should we teach them ?, Information Systems, 2006.

[3] F. David, R. Abreu, Information technology in education: Recent developments in higher education, in Iberian Conference on Information Systems and Technologies, CISTI, 2014, 2014.

[4] W. G. Spady, Outcome-Based Education: Critical Issues and Answers, 1994. 1994.

[5] P. Willmot, M. Bramhall, K. Radley, Using digital video reporting to inspire and engage students, The Higher Education Academy, 2012,

[6] W. A. Almurashi, THE EFFECTIVE USE OF YOUTUBE VIDEOS FOR TEACHING ENGLISH LANGUAGE IN CLASSROOMS AS SUPPLEMENTARY MATERIAL AT TAIBAH UNIVERSITY IN ALULA, 2016.

[7] H. Forbes et al., Use of videos to support teaching and learning of clinical skills in nursing education: A review, Nurse Education Today, 2016. 2016.

[8] G. C. Lee, C. C. Wu, Enhancing the teaching experience of pre-service teachers through the use of videos in web-based computer-mediated communication (CMC), Innovations in Education and Teaching International, 2006. 2006.

[9] S. Ivanova, Using explainer videos to teach web design concepts, in The 13th International Scientific Conference eLearning and Software for Education, $2017,2017$.

[10] K. Kraiger, J. K. Ford, E. Salas, Application of Cognitive, Skill-Based, and Affective Theories of Learning Outcomes to New Methods of Training Evaluation, Journal of Applied Psychology, 1993.

[11] P. Pastor, M. Kalakrishnan, S. Chitta, E. Theodorou, S. Schaal, Skill learning and task outcome prediction for manipulation, in Proceedings - IEEE International Conference on Robotics and Automation, 2011, 2011.

[12] C. Gomathi, V. Rajamani, Skill-based education through fuzzy knowledge modeling for e-learning, Computer Applications in Engineering Education, 2018.

[13] A. G. GREENWALD, Cognitive Learning, Cognitive Response to Persuasion, and Attitude Change, in Psychological Foundations of Attitudes, 1968, 1968.

[14] R. C. Schank, T. R. Berman, K. A. Macpherson, Learning by doing, in Instructional-Design Theories and Models: A New Paradigm of Instructional Theory, 2013, 2013.

[15] M. J. Bezanilla, D. Fernández-Nogueira, M. Poblete, H. Galindo-Domínguez, Methodologies for teaching-learning critical thinking in higher education: The teacher's view, Thinking Skills and Creativity, 2019.

[16] J. Andrews-Todd, C. M. Forsyth, Exploring social and cognitive dimensions of collaborative problem solving in an open online simulation-based task, Computers in Human Behavior, 2020,.

[17] V. Garousi, G. Giray, E. Tuzun, C. Catal, M. Felderer, Closing the Gap between Software Engineering Education and Industrial Needs, IEEE Software, 2020.

[18] L. DE SOUSA, B. RICHTER, C. NEL, The effect of multimedia use on the teaching and learning of Social Sciences at tertiary level: a case study, Yesterday and Today, 2017,

[19] B. R. Robin, The power of digital storytelling to support teaching and learning, Digital Education Review, 2016. 2016.

[20] M. Himanshoo, K. Sharma, Role of ICT in Improving the Excellence of Education, International Journal on Computer Science and Engineering (IJCSE, 2015.

[21] A.-M. Suduc, M. Bîzoi, G. Gorghiu, L.-M. Gorghiu, Digital Images, Video and Web Conferences in Education: A Case Study, Procedia - Social and Behavioral Sciences, 2012.

[22] L. Killian, New Textual Formats: Reading online is re-wiring the human brain and changing how we process information, Dalhousie Journal of Interdisciplinary $\quad$ Management, $\quad \mathbf{5 ( 1 ) ,} 2010$. https://doi.org/10.5931/djim.v5i1.49

[23] P. Churi, K. Mistry, A. Dhruv, S. Wagh, Alchemizing education system by developing 5 layered outcome based engineering education (OBEE) model, in Proceedings - 2016 IEEE 4th International Conference on MOOCs, Innovation and Technology in Education, MITE 2016, 2017, 2017.

[24] J. C. Ortiz-Ordoñez, F. Stoller, B. Remmele, Promoting Self-confidence,
Motivation and Sustainable Learning Skills in Basic Education, Procedia Social and Behavioral Sciences, 2015.

[25] P. Ommundsen, Problem-based learning, in Inspiring Students: Case Studies on Teaching Required Courses, 2013, 2013.

[26] D. Boud, G. I. Feletti, The challenge of problem-based learning, 2013. 2013.

[27] J. R. Savery, T. M. Duffy, Problem based learning: An instructional model and its constructivist framework, Educational Technology, 1995.

[28] S. Crowe, K. Cresswell, A. Robertson, G. Huby, A. Avery, A. Sheikh, The case study approach, BMC Medical Research Methodology, 2011,.

[29] C. Edwards, Life-long learning, Communications of the ACM, 1993.

[30] J. P. Weaver, R. J. Chastain, D. A. DeCaro, M. S. DeCaro, Reverse the routine: Problem solving before instruction improves conceptual knowledge in undergraduate physics, Contemporary Educational Psychology, 2018.

[31] B. Ahn, M. F. Cox, J. London, O. Cekic, J. Zhu, Creating an instrument to measure leadership, change, and synthesis in engineering undergraduates, Journal of Engineering Education, 2014. 